\title{
Health stories that mattered: Feb. 24-28
}

- Federal Liberals have voted in favour of a resolution calling for the decriminalization of voluntary, medically assisted death. The motion comes in anticipation of the vote in Quebec over whether to legalize medically assisted death. If successful, Quebec would be the first province in Canada to legalize such measures.

- The overall rate of reported adverse effects following vaccinations in Ontario was 4.7 per 100000 population in 2012, according to a report published by Public Health Ontario. The largest number of adverse effects reported was secondary to the influenza vaccine and none of the reactions reported were fatal.

- An increase in the number of deceased organ donors in Canada has led to an improvement in the organ donation rate, in part because of increasing public awareness. Canada's overall rate of 15.5 deceased donors per million in 2012 is still lower than other developed nations such as Spain, France, Italy and the US.
- Anesthetist George Doodnaught, 65 , was sentenced to 10 years in prison for the sexual assault of 21 female patients while they were sedated. He plans to appeal the conviction. The College of Physicians and Surgeons of Ontario suspended Doodnaught's licence after receiving 30 complaints of sexual misconduct and will be conducting a disciplinary hearing.

- The federal government is proposing more explicit warning labels for tanning beds and equipment. Ottawa is now conducting public consultation before finalizing the proposed labels, which feature a cancer warning and a detailed list of potential health risks and complications. It is up to individual provinces and territories whether to implement the warnings.

- The Quebec Order of Pharmacists is calling for Health Canada to be more proactive in requiring pharmaceutical companies to report drug shortages. This was prompted by the current shortage of Ritalin (10 mg), which, according to Diane Lamarre, the order's president, could have been prevented with more time and notice to import the medication from other countries.

- The Canadian Institutes of Health Research has launched a Strategy for Patient-Oriented Research, with a view of ensuring that the right patient receives the right intervention at the right time and translating research into practice. Manitoba will open Canada's first SUPPORT (Support for People and Patient-Oriented Research and Trials) Unit; others will follow throughout the country.

- Toronto, Ont., Vancouver, BC, and Ottawa, Ont., are among the Canadian cities that took part in the Seventh Annual International Rare Disease Day Feb. 28. Coordinated by EURORDIS (Rare Diseases Europe), the day will provide an opportunity to increase support and advocacy for the estimated 1 in 12 Canadians affected by a rare disease.- Gordon Giddings, CMAJ

CMAJ 2014. DOI:10.1503/cmaj.109-4749 